\title{
Effectiveness of telemedicine in response to the COVID-19 pandemic
}

\author{
Maria Angela de Souza1* (1), Audrey Cristina Fioretti ${ }^{1}\left(\mathbb{D}\right.$, Aparecida Helena Vincentin $^{1}$ (D), \\ Ricardo Vieira Botelho ${ }^{1}$ (D), Cidia Vasconcellos ${ }^{1}$
}

\section{SUMMARY}

OBJECTIVE: The aim of this study was to evaluate the utility of the telemedicine care model implemented to treat and guide patients with COVID-19 related symptoms and indicators during the pandemic.

METHODS: This is a retrospective study with data collected from the electronic records of standardized forms for assistance. As a way of evaluating the work performed, the number of consultations, types of referrals, efficiency of care, and patient satisfaction were observed. RESULTS: Between April 2 and October 15, 2020, 92 professionals attended 3,660 patients by telemedicine; out of them, 523 (14.3\%) were referred to a COVID-19 attending room, 128 (3.5\%) to other specialties, $123(3.4 \%)$ to a general emergency department, and $2,886(78.9 \%)$ were monitored via home care. Of the total number of patients, $81(2.2 \%)$ were hospitalized, and $13(0.35 \%)$ died. CONCLUSION: Telemedicine offered useful tools for the care, treatment, and monitoring of patients with COVID-19 during the pandemic. The service was considered by most respondents as satisfactory, resolutive, or safe. KEYWORDS: Telemedicine. Pandemics. Coronavirus infection. Patient satisfaction.

\section{INTRODUCTION}

In March 2020, the World Health Organization (WHO) declared the COVID-19 pandemic, caused by the coronavirus SARS-CoV-2 $2^{1,2}$. At that moment, several countries initiated measures to contain the spread of the virus, and in Brazil, social isolation devices and support measures for the health system were developed. On March 23, the government of the state of Sáo Paulo declared a state of public calamity ${ }^{3}$.

Health authorities used diverse methods of epidemiological surveillance to control the spread of the disease. In addition to social isolation, extreme quarantine measures (i.e., lockdown) were adopted, as well as contact tracing, social distancing, and hygiene measures ${ }^{2}$.

Some health institutions implemented telemedicine as a form of remote care to help maintain social distancing ${ }^{1,2,4}$. The digital evolution in recent years has spawned health-related technologies, making telemedicine possible ${ }^{5,2}$.

The Center for Innovation and Management in Telemedicine and Telehealth (Núcleo de Inovação e Gestão em Telemedicina e
Telessauide-NIGT) was created in a large health institution aimed at facing the COVID-19 pandemic. On April 2, 2020, the center started its activities offering medical advice to patients with flulike illness who were suspected of contracting COVID-19, thus avoiding unnecessary visits to the emergency department, as instructed by the WHO and the Brazilian Ministry of Health at the time, to maintain proper social distancing ${ }^{1}$.

The objective of this study was to evaluate the effectiveness of the telemedicine care model implemented to treat and guide patients with flulike illness suspected of COVID-19 during the pandemic.

\section{METHODS}

This study was conducted between April 2 and October 15, 2020. A retrospective study design was used, and data were collected from patients' care standardized electronic health records.

The service was conducted after the patients or the legal guardians signed free and informed consent.

'Instituto de Assistência Médica ao Servidor Público Estadual de São Paulo - São Paulo (SP), Brazil.

*Corresponding author: souzamangela@gmail.com

Conflicts of interest: the authors declare there are no conflicts of interest. Funding: none.

Received on July 08, 2021. Accepted on July 15, 2021. 
Telemedicine was implemented in the following forms: teleappointment, telemonitoring, medical teletriage, teleguidance, and request for a formative second opinion.

The effectiveness of this model was evaluated using the following variables: total number of appointments, demographic data, numerical increase of monthly appointments, types of treatment, and treatment outcomes.

The progress of the disease in the period was evaluated by comparing the proportions of patients assisted and those referred to the COVID-19 emergency department, checking the possible progress of the disease severity, and evaluating the proportion of hospitalization and death.

The patient's opinion of the teleappointment was assessed using a standardized questionnaire and conducted telephonically. The assisted patients answered questions regarding resolvability, satisfaction, safety, and clarity of care. For resolvability and safety, they could answer yes or no. For satisfaction and clarity, they were presented a score from 1-10, with 8-10 indicating excellent, 5-7 regular, and 1-4 poor.

\section{Infrastructure}

A total of 92 physicians recruited to work in telemedicine received prior training on legislation, ambience, ethics, and regulations and then followed by a standardized treatment or referral procedure according to the severity of symptoms. Medical certificates, requests for tests and examinations, and prescriptions were sent by mail or picked up in person.

The appointments resulted in four types of referrals:

(i) patients with suspected coronavirus infection but with a mild condition were instructed to remain at home in social isolation;

(ii) patients with severe signs and symptoms were referred to the COVID-19 emergency department;

(iii) patients with other clinical complaints were referred to related specialties for face-to-face appointments; and

(iv) patients who needed emergency care but were not compatible or suspected of COVID-19 were referred to the general emergency department (adult and child).

Referrals followed a standardized protocol according to risk stratification, for referral to face-to-face evaluation (Table 1).

\section{Statistical analysis}

Demographic data were described by age and sex. Ages were described as mean, standard deviation, and 95\% confidence interval and divided by age groups such as young (0-19 years), adult (20-59), and elderly (60 years and above).

The normality of women and men age distribution was assessed using the Kolmogorov-Smirnov test. The age distribution
Table 1. Risk stratification.

Signs and symptoms of severity that determine the need for face-to-face medical evaluation.

1. Dyspnea (shortness of breath, movement of the nose wings, $\mathrm{O}_{2}<95 \%$ saturation, signs of cyanosis);

2. Persistent fever (does not subside with medications, lasts more than 24 hours, gets higher and higher);

3. Symptoms do not improve over the days;

4. General condition progressively worsening;

5. Occurrence of new symptoms;

6. Changes in the consciousness level, irritability, and mental confusion.

Institutional COVID-19 Crisis Committee.

was not normal $(\mathrm{p}<0.001)$ and was compared with MannWhitney $U$ test. The proportion of patients referred to the COVID-19 emergency department (and not referred) was compared using a chi-square test. The programs used for statistical analysis were Microsoft Excel 2007 (Microsoft Corp., Redmond, WA, USA) and IBM ${ }^{\circledR}$ SPSS $^{\circledR}$ Modeler version 18.0.

\section{RESULTS}

\section{Total number of appointments}

A total of 3,660 patients were assisted during the study period (Figure 1).

\section{Demographic data}

A total of 2,306 women were telemedicine assisted, of which 1,274 (55\%) were adults, 947 (41\%) elderly, and 85 (4\%) young. Of the 1,354 men assisted, 651 (48\%) were adults, 623 (46\%) elderly, and $80(6 \%)$ young. The women-to-men ratio was 1.7 .

The mean age of the patients assisted was $55.6 \pm 17.56$ years (95\%CI $21-90)$. The mean age was $55.35 \pm 17.10$ years $(95 \% \mathrm{CI}$ 21-89) for women and $56.22 \pm 18.71$ years (95\%CI 22-90) for men (Mann-Whitney U test, $\mathrm{p}=0.10$ ).

\section{Increase in the number of appointments}

Teleappointments started in April 2020. There was a linear growth in the number of appointments until May and midJune. Between the end of June and July, the number reached a plateau (Figure 1). The peak occurred in the month of July. Afterward, the number began to progressively decline.

There was no difference in referral to the COVID-19 emergency department between the months surveyed $\left(\chi^{2}=3,818 ; \mathrm{p}=0.70\right)$.

\section{Types of treatment}

This service provided certificates (8), requests for tests and examinations (183), and prescriptions (7) for treatments at home. 


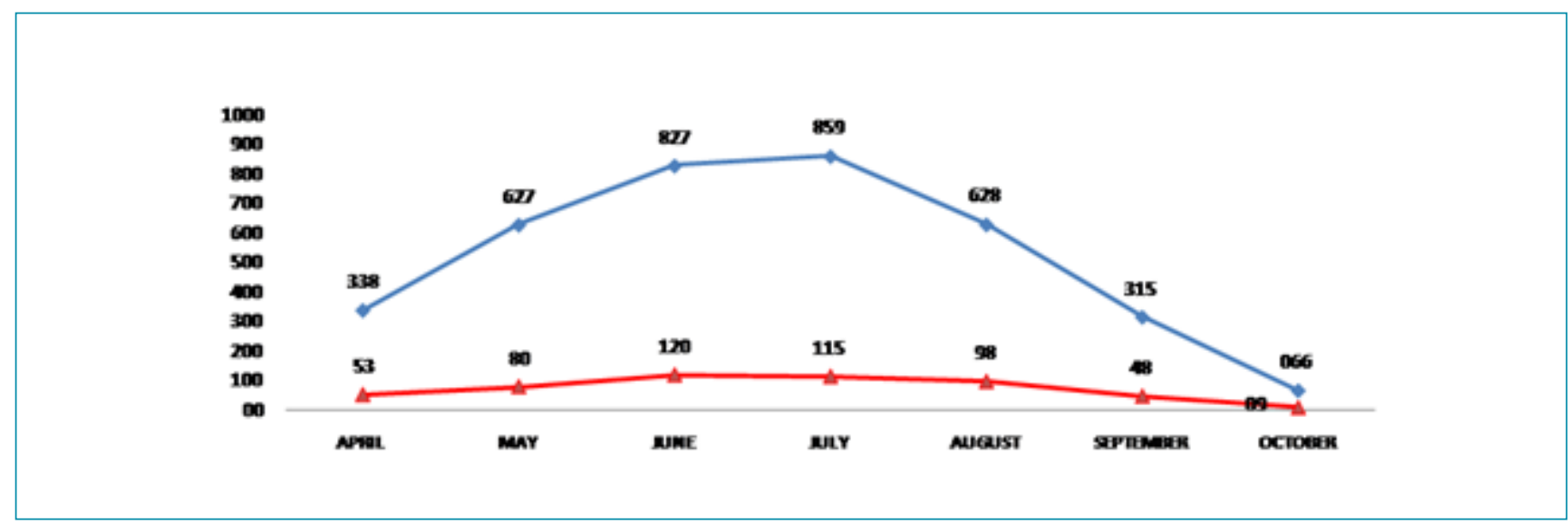

Figure 1. Number of patients attended by month of study (blue). Number of patients referred to the COVID-19 department (red). Number of patients assisted by telemedicine and referred to PS Covid.

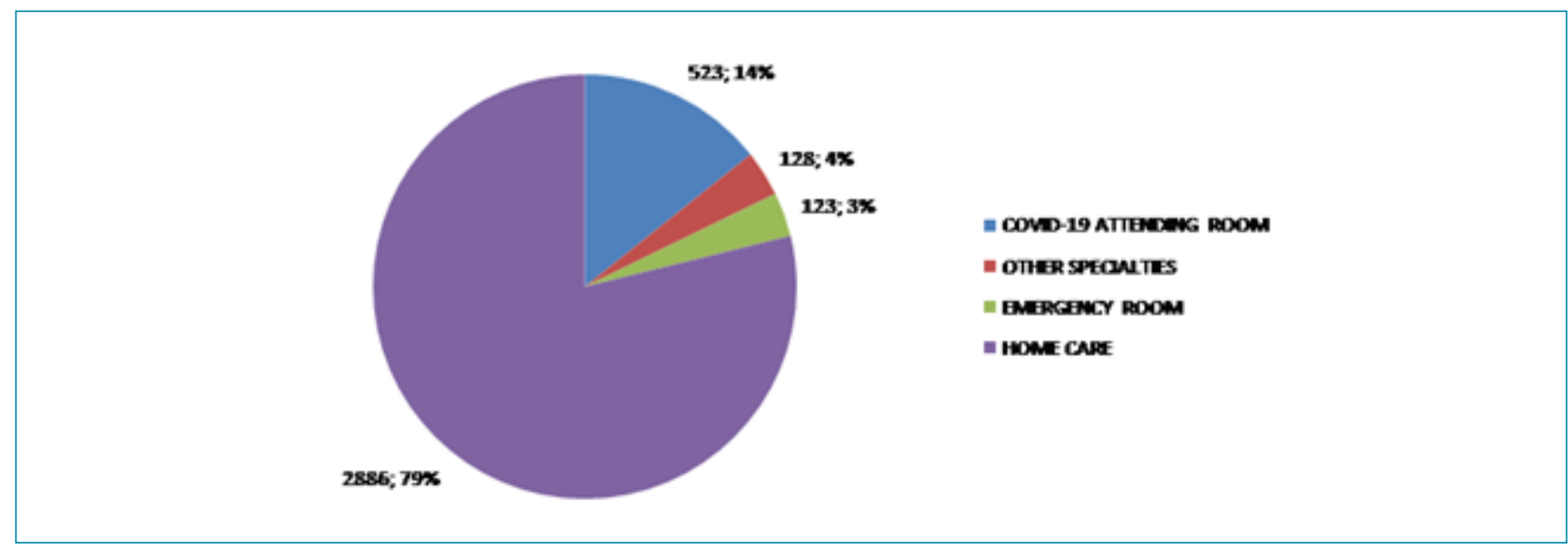

Figure 2. Number and percentage of attending patients referred to the specific departments or specialties. Outcomes.

\section{Service outcomes}

A total of 3,660 patients were assisted. Of these, 523 (14.3\%) were referred to the COVID-19 emergency department; 128 (3.5\%) were referred to other specialties; $123(3.4 \%)$ were referred to the general emergency department; and 2,886 (78.9\%) were monitored via home care. A total of $81(2.2 \%)$ patients were admitted and $13(0.35 \%)$ died (Figure 2).

Regarding death, 8 (62\%) were women and $5(38 \%)$ were men. The mean age of those who died was $74.15 \pm 13.7$ years.

\section{Evaluation of the service}

A total of 2,089 (57\%) patients agreed to participate in the survey.

Satisfaction: $95 \%$ of patients scored 8-10 (excellent), 5\% scored 5-7 (regular), and none scored 1-4 (poor).

Resolvability: $91 \%(1,905)$ reported having their problems solved, and $9 \%$ (184) said their problem had not been solved.

Safety: $88 \%(1,846)$ felt safe, and $12 \%$ (243) did not.
Clarity: 97\% considered it excellent and 3\% regular.

\section{DISCUSSION}

The WHO recommended social isolation to reduce the speed of contagion and protect the health system against overcrowding and avoiding bankruptcy as the main concerns in the fight against the COVID-19 pandemic.

On March 22, 2020, quarantine was decreed in the state of São Paulo as a measure to fight COVID- $19^{3}$ and was extended until June 2021. On September 19, the contingency plan was relaxed (orange phase). At the end of September 2020, the plan went into the green phase (less strict), in line with the results found for the peak and decline. There were at least 11 decrees extending the quarantine until October 2020, the end of this study.

Telemedicine has become an appropriate modality to meet these circumstances. Although telemedicine was already 
regulated in several countries around the world, in Brazil, it was limited to teleconsulting and teleinterconsulting ${ }^{6}$. Due to the pandemic, this service was authorized as a full-on emergency, while the crisis caused by the coronavirus lasts?

The results of this study showed the behavior of patients with suspected COVID-19 who needed guidance and chose virtual appointments. Almost all patients were elderly and adults. A total of $43 \%$ of the patients of the studied institution were elderly, a proportion similar to that found in the appointments (42\%), and the mean age of deaths corresponded to this age group.

A total of $79 \%$ of the patients treated were kept in home care, $4 \%$ had other health problems and were referred to other specialties, and $14 \%$ had moderate or severe symptoms and were referred to face-to-face appointments. Moreover, $2 \%$ of the patients were hospitalized and $0.35 \%$ died.

Another study showed similar data as $85 \%$ of patients with COVID-19 disease had mild symptoms, $15 \%$ had more severe clinical cases, and 5\% required intensive care ${ }^{8}$.

The mortality ofCOVID-19 varied according to time of the pandemic and the location studied. In mid-September, the Information Center at the Johns Hopkins University indicated a mortality rate of 3\% for Brazil, $10.6 \%$ for Mexico, and $9.2 \%$ for Ecuador. In India, at that time, it was at $1.6 \%$, only behind the United States .

Mortality due to COVID-19 in the state of Sáo Paulo during the study period (April 2 to October 15, 2020) was 0.9/1,000. According to the Civil Registry of Deaths portal, in the state of São Paulo, in this period, there were 40,962 deaths for an estimated population of $44,840,384$ inhabitants $(0.9 / 1,000)^{10}$.

In the present study, lethality (mortality due to disease) was evaluated with a result obtained from 3.5/1,000 (13/3,660 patients) ${ }^{11}$. The study by Martinez-Garcia, from March 17 to April 17, 2020, in Spain, found a lethality rate of 6.4/1,000 (2/313 patients) $)^{12}$.
Telemedicine also served to assist patients with other comorbidities who were referred to other treatments ${ }^{12}$. Most patients considered the service good or excellent. One of the most important health systems in the United States, located in California, showed a similar result ${ }^{13}$. In Brazil, in the city of São Paulo, an emergency service identified that more than 50\% of the patients considered the digital triage service acceptable, $90 \%$ felt safe about the physician's conduct, and $72 \%$ considered their complaints fully solved ${ }^{4}$.

\section{CONCLUSION}

Telemedicine provided useful tools for the care, treatment, and monitoring of patients with suspected or confirmed COVID-19 during the pandemic. The patients showed a high level of satisfaction with this type of service.

\section{AUTHORS" CONTRIBUTIONS}

MAS: Conceptualization, Data curation, Formal analysis, Funding acquisition, Investigation, Methodology, Project administration, Resources, Supervision, Validation, Visualization, Writing - original draft, Writing - review \& editing. RVB: Conceptualization, Data curation, Formal analysis, Investigation, Methodology, Supervision, Writing - review \& editing. ACF: Conceptualization, Data curation, Formal analysis, Funding acquisition, Investigation, Methodology, Project administration, Validation, Visualization, Writing - review \& editing. AHV: Conceptualization, Data curation, Software. CV: Conceptualization, Formal analysis, Writing - original draft, Writing - review \& editing.

\section{REFERENCES}

1. Ohannessian R, Duong TA, Odone A. Global telemedicine implementation and integration within health systems to fight the COVID-19 pandemic: a call to action. JMIR Public Health Surveill. 2020;6(2):e18810. https://doi.org/10.2196/18810

2. Caetano R, Silva AB, Guedes ACCM, Paiva CCN, Ribeiro GDR, Santos DL, et al. Challenges and opportunities for telehealth during the COVID-19 pandemic: ideas on spaces and initiatives in the Brazilian context. Cad Saude Publica. 2020;36(5):e00088920. https://doi.org/10.1590/0102$311 \times 00088920$

3. São Paulo. Assembleia Legislativa do Estado de São Paulo. Decreto $n^{\circ}$ 64.881, de 22 de março de 2020. Decreta quarentena no Estado de São Paulo, no contexto da pandemia do COVID-19 (Novo Coronavírus), e dá providências complementares. Brasil; 2020.
4. Lottemberg C, Silva PE, Klajner S. A revolução digital na saúde: como a inteligência artificial e a internet das coisas tornam o cuidado mais humano, eficiente e sustentável. São Paulo: Editora dos Editores; 2019.

5. Brasil. Portaria 467, de 20 de março de 2020. Dispõe em caráter excepcional e temporário, sobre as ações de Telemedicina, com o objetivo de regulamentar e operacionalizar as medidas de enfrentamento da emergência de saúde pública de importância internacional previstas no art. $3^{\circ}$ da Lei $n^{\circ} 13.979$, de 6 de fevereiro de 2020, decorrente da epidemia de COVID-19. Brasil; 2020

6. Brasil. Associação Brasileira de Mantenedoras de Ensino Superior. Resolução CFM n 1.643, de 7 de agosto de 2002. Define e disciplina a prestação de serviços através da Telemedicina. Brasil; 2002. 
7. Brasil. Lei $n^{\circ} 13.989$, de 15 de abril de 2020. Dispõe sobre o uso da telemedicina durante a crise causada pelo coronavírus (SARS-CoV-2). Brasil; 2020.

8. Wu Z, McGoogan JM. Characteristics of and important lessons from the Coronavirus Disease 2019 (COVID-19) outbreak in China: summary of a report of 72314 cases from the Chinese center for disease control and prevention. JAMA. 2020;323(13):1239-42. https://doi.org/10.1001/jama.2020.2648

9. Jones F. COVID-19 o enigma da letalidade: dificuldades para obter o número exato de infectados e de óbitos impõem desafios para se conhecer quão mortal é a doença. Pesquisa FAPESP. 2020 [cited on May 18, 2021]:23-5. Available from: https://revistapesquisa.fapesp.br/o-enigma-da-letalidade

10. Fundação Sistema Estadual de Análise de Dados, Portal de Estatísticas do Estado de São Paulo, Informações dos Municípios Paulistas. Coronavírus. 2021 [cited on Jun. 18, 2021]. Available from: https://www.imp.seade.gov.br/frontend/\#/
11. Portal de Transparência. Especial COVID-19 Painel Registral: óbitos com suspeita ou confirmação de COVID-19. 2021 [cited on Jun. 18, 2021]. Available from: https://transparencia. registrocivil.org.br

12. Martínez-García M, Bal-Alvarado M, Santos Guerra F, AresRico R, Suárez-Gil R, Rodriguez-Alvarez A, et al. Telemedicina con telemonitorizaciónen el seguimiento de pacientes con COVID-19/Tracing of COVID-19 patients by telemedicine with telemonitoring. Rev Clin Esp. 2020;220(8):472-9. https://doi. org/10.1016/j.rce.2020.05.013

13. Wicklund E. Kaiser Permanente sees good results with videobased telehealth. Researchers with the California-based health system found high patient satisfaction rates and positive outcomes in an analysis of video-based telehealth encounters between 2015 and 2017. 2018 [cited on Feb. 8, 2021]. Available from: https://mhealthintelligence.com/news/kaiserpermanente-sees-good-results-with-video-based-telehealth 